TAPROBANICA, ISSN 1800-427X. April, 2012. Vol. 04, No. 01: pp. 37-41.

(C) Taprobanica Private Limited, Jl. Kuricang 18 Gd.9 No.47, Ciputat 15412, Tangerang, Indonesia.

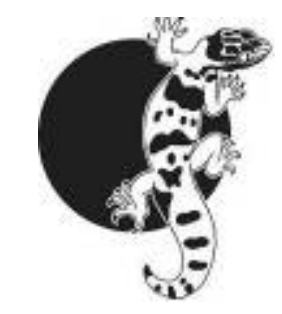

\title{
GASTROINTESTINAL PARASITES OF CAPTIVE PRIMATES IN THE NATIONAL ZOOLOGICAL GARDENS OF SRI LANKA
}

Sectional Editor: Colin Chapman

Submitted: 05 August 2011, Accepted: 15 April 2012

Umanga C. Gunasekera ${ }^{1,3}$, Susiji Wickramasinghe ${ }^{1}$, Ganga Wijesinghe ${ }^{2}$ and R. P. V. J. Rajapakse ${ }^{1}$

\footnotetext{
${ }^{1}$ Department of Pathobiology, Faculty of Veterinary Medicine \& Animal Science, University of Peradeniya, Sri Lanka

${ }^{2}$ The National Zoological Gardens of Sri Lanka, Dehiwala, Sri Lanka

E-mail: ${ }^{3}$ umavet@yahoo.com
}

\begin{abstract}
Fifteen species of primates from different geographic areas are living in captivity at the National Zoological Gardens of Sri Lanka. As a result of limited space in the Zoo and ever increasing visitors, there is a possibility to increase the incidence of human animal contact. Therefore, it is important to identify potential parasitic infections that can be transferred from humans to animals and vise versa. In the present study, the primates were investigated for the gastrointestinal parasites. Total of 85 fecal samples were collected from all the species and examined for the presence of helminthes and protozoa. Balantidium sp., Entamoeba coli, Giardia sp., Blastocystis sp. and coccidial oocytes including Cryptosporidium sp. oocysts were identified. Furthermore, Nematodes and Cestodes were also recorded.
\end{abstract}

Key words: Helminthes, nematodes, cestodes, protozoa, parasitic infections, oocytes.

\section{Introduction}

Several kinds of gastrointestinal parasites were reported in both captive and non-captive primates in the world (Brack, 1987; Bruno et al., 2007; Hendricks, 1977; Muriuki et al., 1998; Soulsby, 1982; Tachibana et al., 2009). In Sri Lanka few studies have been carried out on identifying the gastrointestinal parasites in the primates and only handful of publications available on the captive animals in the zoo (e.g. Amarasinghe et al., 2009) while there are few on non-captive fauna in the zoo premises (Karunarathna et al., 2007; 2008). From Sri Lankan primates helminthes protozoa are reported in Macaca sinica (Dewit et al., 1991; Ekanayake et al., 2004) in the wild. The reported species were Trichostrongylus sp., Strongyloid sp., Oesophagustomum spp., Cestoda sp. and Hymenolepsis sp. The identified ciliates were Giardia sp., Balantidium sp. Entamoeba histolytica, Entamoeba coli, Entamoeba hartmanni and Blastocystis spp. and the coccidian parasite Cryptosporidium sp. The genus level identification was done using the PCR method. Cryptosporidium and other protozoan infections (Entamoeba sp., Iodamoeba sp., Chilomastix sp. and Balantidium 
sp.) in wild Trachypithecus vetulus are also reported (Ekanayake et al., 2004).

\section{Materials and Methods}

Study Area: The National Zoological Gardens is approximately 10 hectares in extent. It is located in the wet zone of Sri Lanka (6 $6^{\circ} 1^{\prime} 21.48^{\prime \prime}$ - 6 $6^{\circ} 51^{\prime}$ $30.30 ” \mathrm{~N}$ and $79^{\circ} 52^{\prime} 20.08^{\prime \prime}-79^{\circ} 52^{\prime} 33.99 ” \mathrm{E}$ ) (Karunarathna et al., 2008) at a mean elevation of $25 \mathrm{~m}$ above sea level. The nearest city is Dehiwala (2 km) and its proximity to the city of Colombo (11 $\mathrm{km})$ makes it an easily accessible location for the potential visitors (Weinman, 1957). There are 15 species of primates in the national zoo and apart from that large numbers of wild animal species are housed in the premises. Approximately 100 species of mammals, 110 species of birds, 35 species of reptiles, butterflies and marine vertebrates constitute this collection. There are 16 sections in the national zoo.

Sample collection: Study period was 7 months commencing from August 2009 up to February 2010. Total of 85 fecal samples were collected throughout the study period. Fresh voided fecal samples were collected from the ground in the morning and they were transferred to the laboratory. The number of animals in each cage and the number of samples collected from each cage was recorded (Table 1). Sample collection was done once per every month during the study period. For the transportation, air tight samples were kept in styrofoam boxes with ice.

Table 1: Details of the samples collected and examined.

\begin{tabular}{|c|c|c|c|}
\hline Common name & Scientific name & $\begin{array}{l}\text { No. of animals } \\
\text { in each cage }\end{array}$ & $\begin{array}{c}\text { No. of samples } \\
\text { collected \& } \\
\text { examined }\end{array}$ \\
\hline \multicolumn{4}{|c|}{ Section 03} \\
\hline Siamang gibbon & Symphalangus syndactylus & 1 & 3 \\
\hline Grey langur & Semnopithecus entellus & 1 & - \\
\hline Toque monkey & Macaca sinica & 8 & 4 \\
\hline \multicolumn{4}{|c|}{ Section 08} \\
\hline Japanese monkey & Macaca fuscata & 3 & 2 \\
\hline Formosan monkey & Macaca cyclopis & 1 & 3 \\
\hline Siamang gibbon & Symphalangus syndactylus & 1 & - \\
\hline Silver leaf monkey & Trachypithecus cristatus & 7 & 6 \\
\hline White handed gibbon & Hylobates lar & 1 & 2 \\
\hline Squirrel monkey & Saimiris ciureus & 1 & 5 \\
\hline Capuchin & Cebus capucinus & 1 & 6 \\
\hline Sooty mangabey & Cercocebus aterrimus & 1 & 6 \\
\hline \multicolumn{4}{|c|}{ Section 11} \\
\hline Orang-utan & Pongo pygmaeus & 4 & 5 \\
\hline Toque monkey & Macaca sinica & 4 & 5 \\
\hline Grey langur & Semnopithecus entellus & 2 & 4 \\
\hline Japanese monkey & Macaca fuscata & 2 & 5 \\
\hline \multicolumn{4}{|c|}{ Sections 13 and 14} \\
\hline Chimpanzees & Pan troglodytes & 6 & 5 \\
\hline \multicolumn{4}{|c|}{ Section 15} \\
\hline Hamadryas baboon & Papio hamadryas & 1 & 4 \\
\hline Toque monkey & Macaca sinica & 5 & 3 \\
\hline Hooded Capuchin & Cebus apella & 1 & 3 \\
\hline Black cheeked white nosed monkey & Cercopithecus ascanius & 1 & 2 \\
\hline Patas monkey & Erythrocebus patas & 1 & 2 \\
\hline Hamadryas baboon & Papio hamadryas & 1 & 4 \\
\hline Grey langur & Semnopithecus entellus & 4 & 5 \\
\hline
\end{tabular}


Identification: To determine the presence of parasites/eggs/cyst, following techniques were performed.

\section{Direct fecal smear observation}

Iodine stain: Lugo’s iodine was used.

To isolate helminthes eggs: salt flotation technique

Detection of protozoan cysts: sugar flotation technique and/or Acetic acid-ether concentration technique

Identification of the Cryptosporidium oocysts: Ziehl-Neelsen staining technique.

Species identification: PCR (Gene Amp ${ }^{\circledR}$ PCR system 9700) was done using genomic DNA and $E$. coli specific primers (Forward-5' GAATGTCAAAGCTAATACTTGACG-3' and Reverse-5'GATTTCTACAATTCTCTTGGCATA3'). Promega Wizard ${ }^{\circledR}$ Genomic purification kit was used for the DNA extraction.PCR conditions were used as previously described by Tachibana et al. (2009). Amplified products were visualized in 1.5\% agarose gel containing Ethidum bromide. DNA ladder (100 bp) was used as a marker to determine the length of the amplicons.
Culturing procedure of the protozoa: After morphological identification for further identification of protozoa, some of the fresh positive samples are directly cultured in the modified Tanabe-Chiba medium at $37^{\circ} \mathrm{C}$. Two sub cultures were done every twenty four hours later consequently according to Nilles-Bije \& Rivera (2009)

\section{Results and discussion}

In the present study, we have identified several species of protozoa (Cryptosporidum sp., Balantidium sp., Blastocyst sp., Entamoeba sp., Giardia sp., and coccidian) in the chimpanzee, orang-utan, hamadryas baboon, Japanese macaque, siamang, toque monkey, grey langur, silvered leaf monkey, sooty Mangabey and Formosan monkey (Fig.1). Two protozoan cysts were not identified morphologically (morpho 1, morpho 2) due to the variations in shape, size and the internal structures. In PCR study, we successfully amplified 180 bp in length fragment using $E$. coli specific primers. Therefore, we confirmed that the species as a pathogenic E. coli. Furthermore, Nematode larvae (hook worm) and eggs (Ascaris, Strongyle and Trichuris types) were identified in some of the primate species (Table 2).

Table 2: The helminth eggs protozoan cysts detected in each primate species

\begin{tabular}{|c|c|c|c|c|c|c|c|c|c|c|c|c|c|}
\hline \multirow[t]{2}{*}{ Primate species } & \multicolumn{13}{|c|}{ Hook Trichuri: Strongyle Nematod Ascaris Crypto Cocci Balanti Blast Entam Giardic Morph Morpho } \\
\hline & worr & leggs & eggs & larvae & eggs & & & & cyst & spp. & spp. & 1 & 2 \\
\hline \multicolumn{3}{|l|}{ Symphalangus syndactylus } & +ve & & +ve & & + ve & & & & & & \\
\hline Semnopithecus entellus & +ve & & & & & & & & & $+\mathrm{ve}$ & +ve & +ve & \\
\hline Macaca sinica & +ve & +ve & & +ve & +ve & & & +ve & +ve & & & & +ve \\
\hline Macaca fuscata & & & & & & +ve & & & +ve & +ve & & & \\
\hline Macaca cyclopis & & & & & +ve & & & & & & & & +ve \\
\hline Presbytis cristata & & & & & & & & & & +ve & & & \\
\hline \multicolumn{14}{|l|}{ Saimiri sciureus } \\
\hline Cebus capucinus & & & +ve & & & & & & & & & & \\
\hline Cercocebus atys & & & & & & +ve & & & & & & & \\
\hline Pongo pygmaeus & +ve & & & & & +ve & & +ve & & & & & \\
\hline Pan troglodyte & & & & +ve & & & +ve & +ve & & & & & \\
\hline Papio hamadryas & & +ve & & & & +ve & +ve & +ve & & & & & \\
\hline \multicolumn{14}{|l|}{ Cebus apella } \\
\hline \multicolumn{14}{|l|}{ Cercopithecus ascanius } \\
\hline Erythrocebus patas & & & & & & & & & & & & & \\
\hline
\end{tabular}



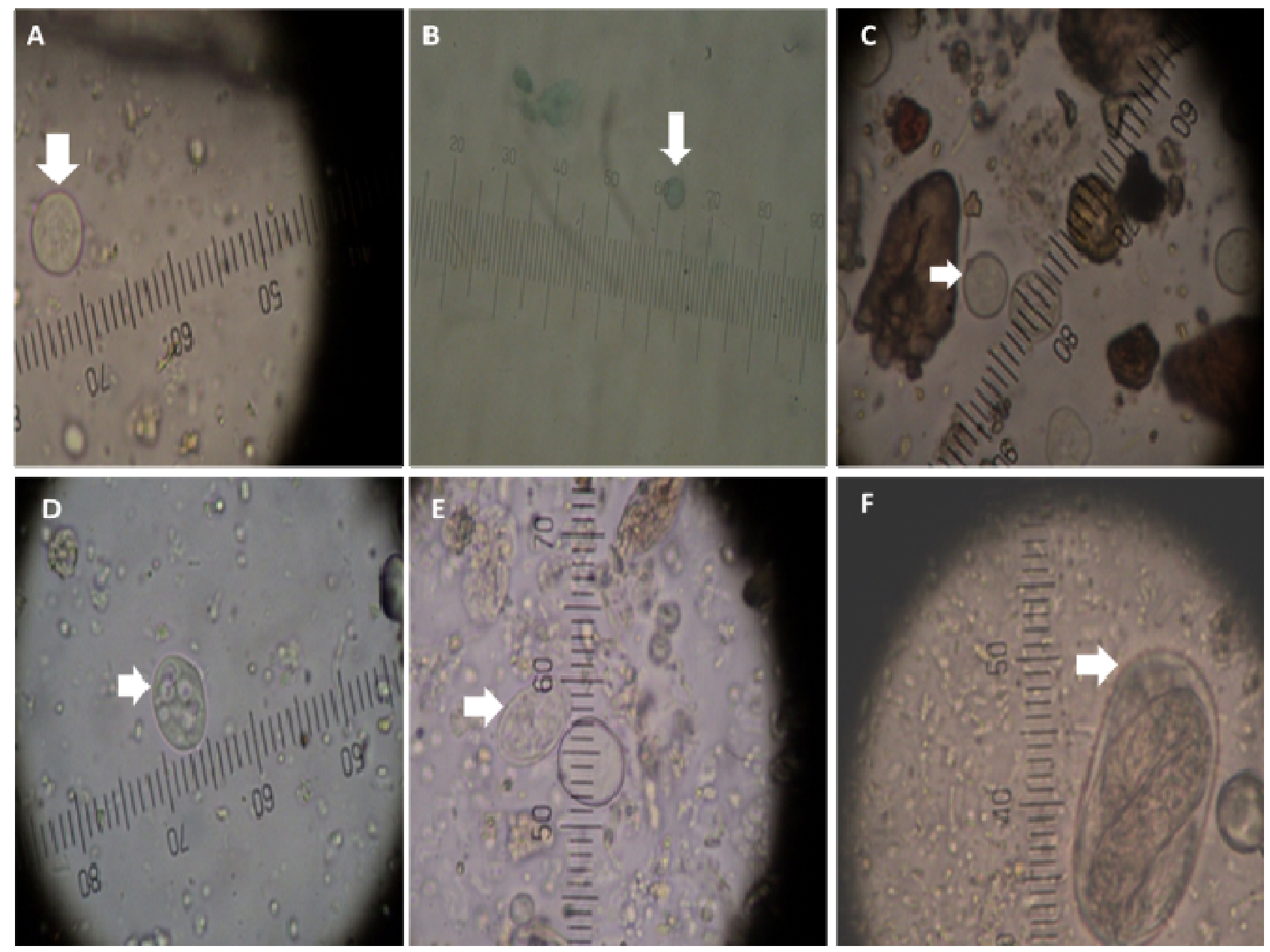

Figure 1: morphology of some of the protozoan cysts and nematode eggs identified (Magnification $\times$ 40) (A) Morpho 1 sp.; (B) Blastocystis cyst; (C) Enatamoeba cyst; (D) Giardia cyst; (E) Nematode egg; (F) Cryptosporidium cyst

The presences of gastrointestinal parasites have been reported in both captive and non-captive primates. Rarely, infected primates show clinical signs of particular parasitic diseases. More often, parasitic diseases are contracted when animals are immunosuppressed due to malnutrition, stress or as a result of heavy parasitic load.

Ziehl-Neelsen staining technique was used for the identification of Cryptosporidium oocysts. These oocysts were difficult to demonstrate during routine fecal examination because of the smaller size (size 2-6 $\mu \mathrm{m}$ ). Therefore, acid-fast technique was used for the detection of oocysts. Originally the oocyst after staining should appear bright red. Due to the staining technical errors here it appears in slight pinkish colour. Cryptosporidium species is the most common protozoa found among the monkeys. It was reported that these monkeys are frequenting the areas and water that has been soiled by humans (Ekanayake et al., 2004). Similarly, in our study, we found that Cryptosporidium sp. was presented in primates of Dehiwala Zoo. Furthermore, there were no new animals introduced to the already existing primate population during the study period. Therefore, there is a possibility that the primates have acquired it from contaminated food, human contact or environment. To confirm that it is the same parasite genus that is affecting both nonhuman primates and humans further detailed studies should be carried out at both morphological and molecular level. It is also possible that the primate is the preferred host and therefore the humans are not infected.

Gasser et al. (2004) screening of the workers for suspected zoonoses is also a must in the same manner. In this study most of the parasite identification has been done only up to the genus level. Further studies should be carried out to determine the zoonotic potential of the identified parasitic spp.

Coccidial oocysts were detected in the chimpanzee (Pan troglodytes). These primates had diarrhea and had been treated previously. It might be due to 
cocccidial infection. Although, coccidial oocysts were recorded in several other species of primates during the study period however, they did not show any clinical signs. In North America, researchers have identified Coccidial oocysts in chimpanzee. Moreover, it has been confirmed as Isospora species based on morphology (Hendricks, 1977). Cestodes and Trichuris species were also found in some primates.

Balantidium species and Ascaris eggs were isolated in Toque monkeys. Balantidium species reported in our study is morphologically similar to Balantidium coli. In addition, we were able to identify Giardia sp., Entamoeba coli and Blastocystis sp. in most of the primates. However, they did not show any clinical signs of infection.

The culturing of the protozoa was done to perform a more accurate identification using the motile trophozoites. For culturing, both fresh and filtered positive samples were used. Filtered sample was used to reduce the inhibiting factors (Nilles-Bije \& Rivera, 2009). However, it was not successful. This may be due to culturing of cysts instead of motile trophozoites or otherwise.

We suspect that primates acquired these parasitic infections mainly through contaminated foods or environment. Other concerns are stocking density of primates and the same keeper handling the different species of animals. Therefore, further studies are required to determine the source of parasitic infection.

\section{Acknowledgements}

Authors would like to thank K. B. A. T. Bandara for the technical assistance during the study.

\section{Literature cited}

Amarasinghe, A. A. T., M. S. Botejue, L. E. Harding, 2009. Social behaviours of captive Trachypithecus cristatus (mammalia: cercopithecidae) in the national zoological gardens of Sri Lanka. Taprobanica, 1 (1): 66-73.

Brack, M., 1987. Agents transmissible from simians to man. Springer-verlag, London: 454.

Bruno B. C., A. Belltto, X. M. Francois, 2007. Wild life, exotic pets and emerging zoonoses. Emerging Infectious Disease, 13 (1): 6-11.

Dewit I., P. J. Dittus, J. Vercruysse, A. Eileen, D. I. Gibson, 1991. Gastro-intestinal helminths in a natural population of Macaca sinica and Presbytis sp. at Polonnaruwa, Sri Lanka Primates, 32 (3): 391-395.
Ekanayake, K., A. Arulkanthan, N. U. Horadagoda, G. K. M. Sanjeevani, R. Kieft, S. Gunathilaka, P. J. Dittus, 2004. Prevalence of Cryptosporidium and other parasites enteric parasites among wild nonhuman primates in Polonnaruwa, Sri Lanka. The American journal of tropical medicine and hygiene, 74 (2); 322-329.

Gasser, R. B., J. M. de Gruijter and A. M. Polderman, 2009. The utility of molecular methods for elucidating primate-pathogen relationships the Oesophagostomum bifurcum example: 47-62. In: Primate parasite ecology: the dynamics and study of host-parasite relationships, M. A. Huffman and C. A. Chapman (eds.). Cambridge, UK, Cambridge University Press.

Hendricks, L. D., 1977. Host range characteristics of the primate coccidian, Isospora arctopitheci Rodhain, 1933 (Protozoa: Eimeriidae). The Journal of Veterinary Parasitology, 63: 32-33

Karunarathna, D. M. S. S., A. A. T. Amarasinghe, P. I. K. Pebotuwage and A. A. D. S. Udayakumara, 2007. A study of the non captive avifaunal diversity in the National Zoological Gardens, Dehiwala, Sri Lanka. Siyoth, 2 (2): 25-29.

Karunarathna, D. M. S. S., A. A. T. Amarasinghe and A. De Vos, 2008. Preliminary notes on the monitor lizards (Family: Varanidae) within the National Zoological Gardens (NZG) Dehiwala, Colombo District, Sri Lanka. Biawak, 2 (3): 109-118.

Muriuki S. M. K., Murugu R. K., Munene E., Karere G.M., Chai D.C., 1998. Some gastrointestinal parasites of zoonotic(public health) importance commonly observed in old world non-human primates in Kenya. Acta Tropica 71(1): 73-82.

Nilles-Bije, M. L. and L. W. Rivera, 2009. Ultra structural and molecular characterization of Balantidium coli isolated in the Philippines. Parasitology Research, 106: 387-394.

Soulsby, E. J. L., 1982. Helminths, Arthropods and Protozoa of Domesticated Animals. $6^{\text {th }}$ edition, Bailliere Tindall, London: 56-58.

Tachibana, H., T. Yanagi, A. Akatsuka, S. Kobayashi, H. Kanbara, V. Tsutsumi, 2009. Isolation and characterization of potentially virulent species Entamoeba nuttalli from captive Japanese macaques. Parasitology, 136 (10): 1169-1177.

Weinman, A. N., 1957. A zoological guide to the Zoological Gardens of Ceylon. Government press of Ceylon: 73. 